\title{
Mapping occipital bone thickness using computed tomography for safe screw placement
}

\author{
Tomonori Morita, MD, ${ }^{1}$ Tsuneo Takebayashi, MD, PhD, ${ }^{1}$ Hiroyuki Takashima, PhD, ${ }^{1}$ \\ Mitsunori Yoshimoto, MD, PhD, ${ }^{1}$ Kazunori Ida, MD, PhD, ${ }^{1}$ Katsumasa Tanimoto, MD, PhD, ${ }^{1}$ \\ Hirofumi Ohnishi, MD, PhD, ${ }^{2}$ Hiroyoshi Fujiwara, MD, PhD, ${ }^{3}$ Masateru Nagae, MD, $\mathrm{PhD},{ }^{3}$ and \\ Toshihiko Yamashita, MD, PhD'1
}

\begin{abstract}
Departments of ${ }^{1}$ Orthopedic Surgery and ${ }^{2}$ Public Health, Sapporo Medical University School of Medicine, Sapporo, Hokkaido; and ${ }^{3}$ Department of Orthopedic Surgery, Graduate School of Medical Science, Kyoto Prefectural University of Medicine, Kyoto, Japan
\end{abstract}

\begin{abstract}
OBJECT Safe and effective insertion of occipital bone screws requires morphological analysis of the occipital bone, which is poorly documented in the literature. The authors of this study present morphological data for determining the area of screw placement for optimal internal fixation.
\end{abstract}

METHODS The subjects of this institutional review board-approved retrospective study were 105 individuals without head and neck disease who underwent CT imaging at the authors' hospital. There were 55 males and 50 females, with a mean age of 57.1 years (range 20-91 years). Measurements using CT were taken according to a matrix of 55 points following a grid with 1-cm spacing based on the external occipital protuberance (EOP).

RESULTS The maximum thickness of the occipital bone was at the level of the EOP at $16.4 \mathrm{~mm}$. Areas with thicknesses $>8 \mathrm{~mm}$ were more frequent at the EOP and up to $2 \mathrm{~cm}$ in all directions, as well as up to $1 \mathrm{~cm}$ in all directions at a height of $1 \mathrm{~cm}$ inferiorly, and up to $3 \mathrm{~cm}$ from the EOP inferiorly. The male group tended to have a thicker occipital bone than the female group, and the differences were significant around the EOP. The ratio of the trabecular bone to the occipital bone thickness was $>30 \%$ in the central region. At positions more than $2 \mathrm{~cm}$ laterally, the ratio was $<15 \%$, and the ratio gradually decreased further laterally.

CONCLUSIONS Screws that are $8 \mathrm{~mm}$ long can be placed in the area extending $2 \mathrm{~cm}$ laterally from the EOP at the level of the superior nuchal line and approximately $3 \mathrm{~cm}$ inferior to the center. These results suggest that it may be possible to effectively insert a screw over a wider area than the conventional reference range.

http://thejns.org/doi/abs/10.3171/2014.11.SPINE14624

KEY WORDS morphological analysis; occipital bone; occipitocervical fusion; thickness; technique

I NSTABILITY and deformity of the occipital bone and upper cervical spine, including the atlantoaxial joint, are serious pathological conditions that can be life threatening. The main causes are congenital malformations, degenerative diseases, infections, rheumatoid arthritis, trauma, and tumors. The most common intervention for instability at the craniocervical junction is posterior fixation of the occipital bone to the cervical vertebrae. Whereas most fixation methods initially involved only bone grafts, $, 15,18$ recent studies have proposed surgical methods using implants, such as the wire-rod method., ${ }^{4,5,20,21}$ In recent years, the screw-rod method has been gaining popular- ity because it provides instantaneous fixation stability., 1,212 This method is consistently associated with an $80 \%-100 \%$ union rate for the occipital cervical spine. $1,2,4,7,12,13,16,19,22,24$ The main complications are screw loosening, implant failure, $, 2,7,16,19$ and dural tears while drilling the holes for the occipital bone screws $(<4.2 \%)^{1,4,12}$

Safe and effective insertion of occipital bone screws requires morphological analysis of the occipital bone, which is poorly documented in the literature. However, a few detailed reports cover this, ,3, $, 10,14,17,23$ although no reports have been published in Japan to date. To achieve stable fixation, a screw $>8 \mathrm{~mm}$ in length should be inserted at the center

ABBREVIATIONS EOP = external occipital protuberance; $I C C=$ intraclass correlation coefficient. SUBMITTED June 23, 2014. ACCEPTED November 4, 2014.

INCLUDE WHEN CITING Published online May 15, 2015; DOI: 10.3171/2014.11.SPINE14624.

DISCLOSURE The authors report no conflict of interest concerning the materials or methods used in this study or the findings specified in this paper. 
of the occipital bone. ${ }^{11}$ Therefore, in the present study, we used CT to map areas with occipital bone thicknesses $>8$ $\mathrm{mm}$, and we determined the ratio between trabecular bone and total occipital bone thickness in individuals without head and neck disease.

\section{Methods}

\section{Subject Selection}

In this institutional review board-approved retrospective study, we reviewed data for individuals without head and neck disease who had undergone CT scanning (Aquilion CX, Toshiba) at our hospital. Exclusion factors were brain or cervical disease, collagen diseases (for example, rheumatoid arthritis), and disorders of calcium metabolism. Written informed consent was obtained from all participants.

\section{Measurement Technique}

The external occipital protuberance (EOP) was used as a reference point to measure the thickness of the occipital bone on arbitrary CT slices. The surface was divided into $1-\mathrm{cm}$ segments extending laterally for $5 \mathrm{~cm}$ and $1-\mathrm{cm}$ segments extending inferiorly for $4 \mathrm{~cm}$. Therefore, $11 \times$ 5 sites were created in each patient (Fig. 1). The position of the EOP was designated as Level 0 , and the position 1 $\mathrm{cm}$ below that was designated as Level 1. Similarly, the median sagittal plane crossing the EOP was considered as a reference and divided into $1-\mathrm{cm}$ segments on the right side (R1-R5) and left side (L1-L5). Two independent orthopedic surgeons obtained the CT measurements using Zio Term 2009 software (Ziosoft Inc.), which allows cross sections in arbitrary directions. The thickness of the occipital bone was measured in units of $0.1 \mathrm{~mm}$ orthogonal to the tangent at each measurement site. In addition, the trabecular bone thickness was measured in the same direction, and we determined the ratio of the trabecular bone to the occipital bone thickness.

\section{Statistical Analysis}

All statistics were conducted using SPSS version 20.0 (IBM Inc.). Data were expressed as the means \pm standard deviations. The Student t-test was used to compare parameters between males and females, and the significance level was set at $p<0.05$. Interobserver reliability was assessed by intraclass correlation coefficient (ICC) analysis. The relationships between patient age and the thickness of the occipital bone were estimated using Spearman's rank correlation because age and thickness did not show normal distribution.

\section{Results}

One hundred five patients, composed of 55 males and 50 females, with a mean age of 57.1 years (range 20-91 years), were the subjects of this analysis. The average thickness of the occipital bone, measured at 1-cm intervals in every direction, is presented in Table 1 . The EOP had the greatest thickness, with average values of $17.5 \pm$ $3.0 \mathrm{~mm}$ (range $12.5-29.4 \mathrm{~mm}$ ) in males and $15.3 \pm 3.0$ $\mathrm{mm}$ (range $10.5-23.5 \mathrm{~mm}$ ) in females. At each level, the
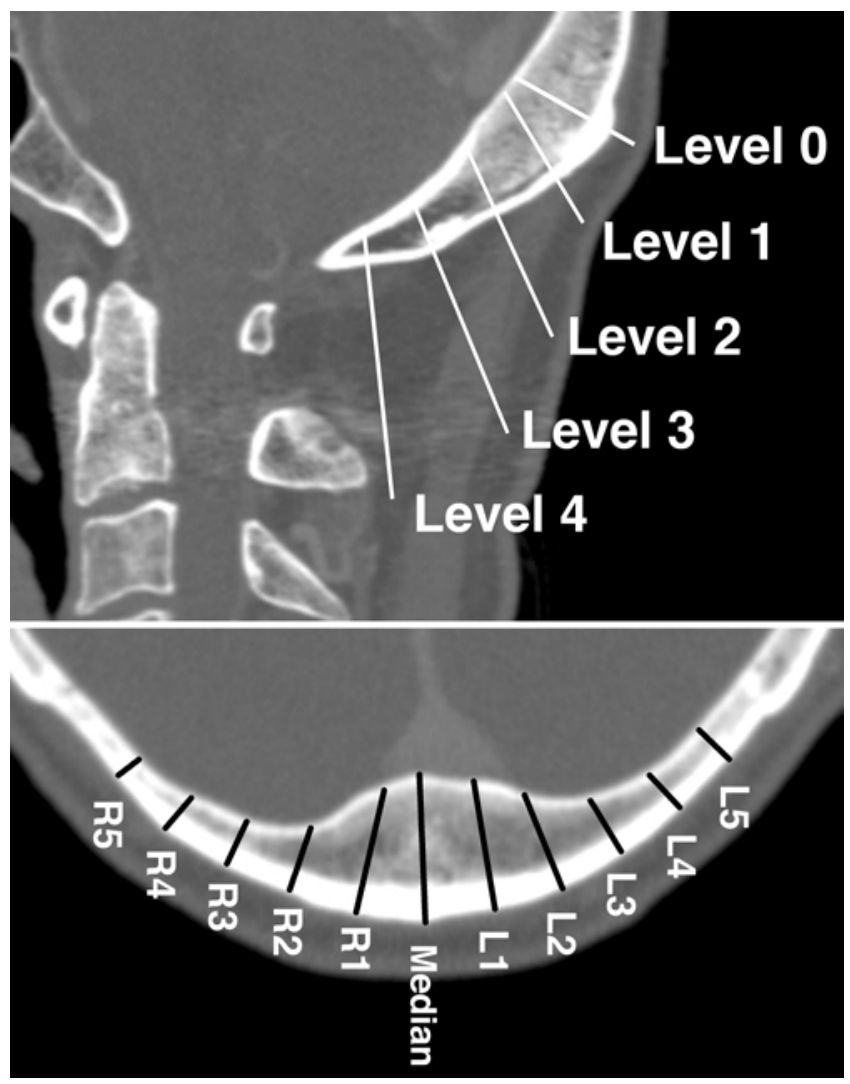

FIG. 1. Computed tomography measurements of the occipital bone. Upper: Sagittal plane showing slices of the EOP. The points represent $1-\mathrm{cm}$ segments using the EOP as a reference, for a distance up to $4 \mathrm{~cm}$. From these points, cross sections were created orthogonally to the external cortical bone. Lower: Axial plane showing points created at each level in 1-cm segments laterally in both directions using the EOP as a reference, for a distance up to $5 \mathrm{~cm}$. The respective distances orthogonal to the cortical bone were measured.

maximum thickness was located in the central region. At Levels 0 and 1 , the values decreased laterally in a linear fashion. At Levels 2, 3, and 4, the values became lower (thinner) and then higher (thicker) again. Areas with thicknesses $>8 \mathrm{~mm}$ were more frequent at the EOP and up to 2 $\mathrm{cm}$ in all directions, as well as up to $1 \mathrm{~cm}$ in all directions at a height of $1 \mathrm{~cm}$ inferiorly, and up to $3 \mathrm{~cm}$ from the EOP inferiorly. There was no significant difference in the proportion of male and female subjects with an EOP $>8 \mathrm{~mm}$ thick; however, the male group tended to have a thicker occipital bone than the female group, and the differences were significant around the EOP. The ratio of trabecular bone to occipital bone thickness was $>30 \%$ in the central region. At positions $>2 \mathrm{~cm}$ laterally, the ratio was $<15 \%$, and the ratio gradually decreased further laterally (Table 2). Measurement of occipital bone thickness demonstrated good interrater reliability (ICC $=0.85$ ). No correlation was observed between patient age and the thickness of the occipital bone at the EOP $(r=0.047, p=0.637)$, and the other points showed similar findings.

\section{Discussion}

Regarding occipital cervical fusion, long-term halo- 

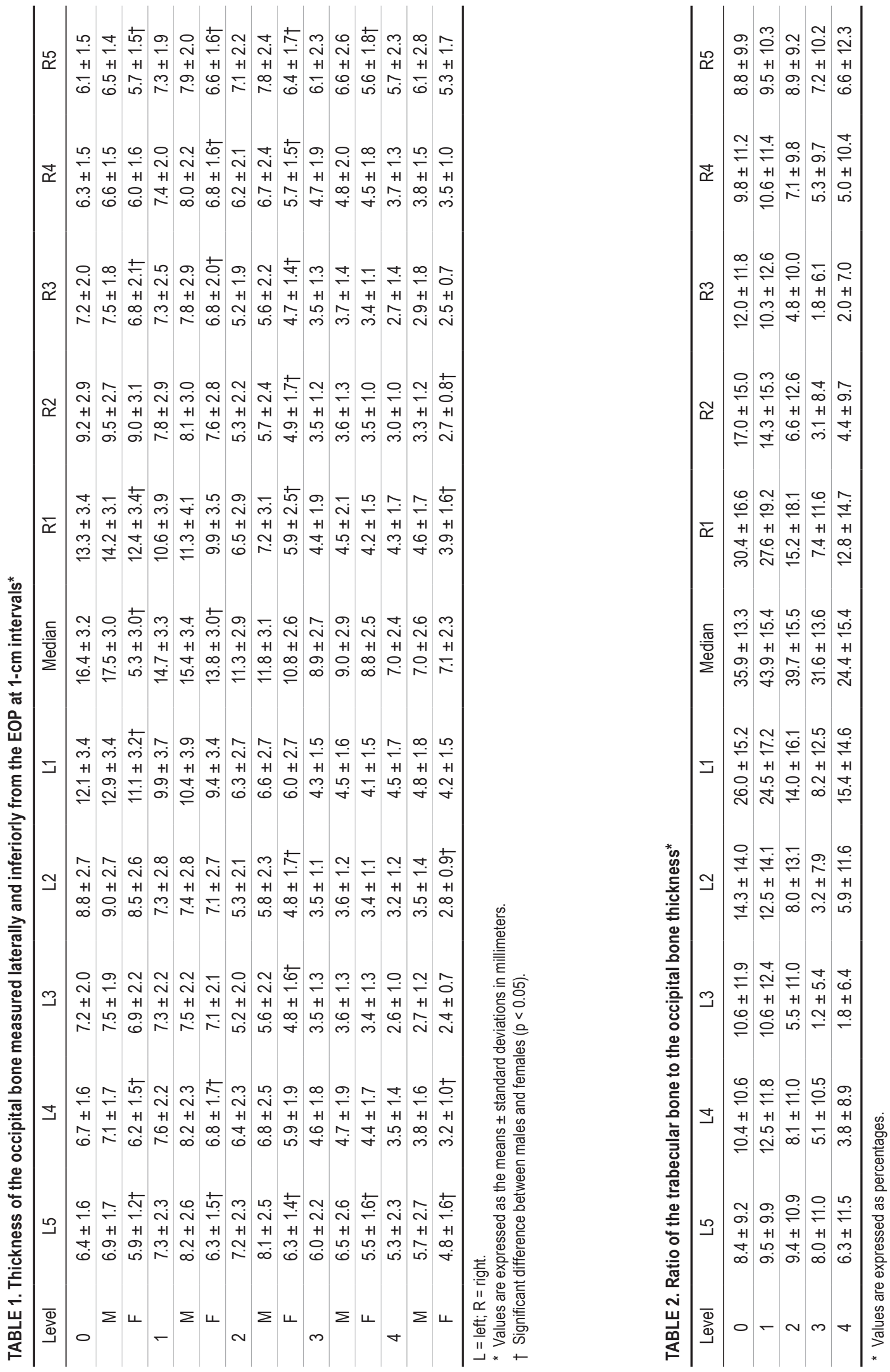

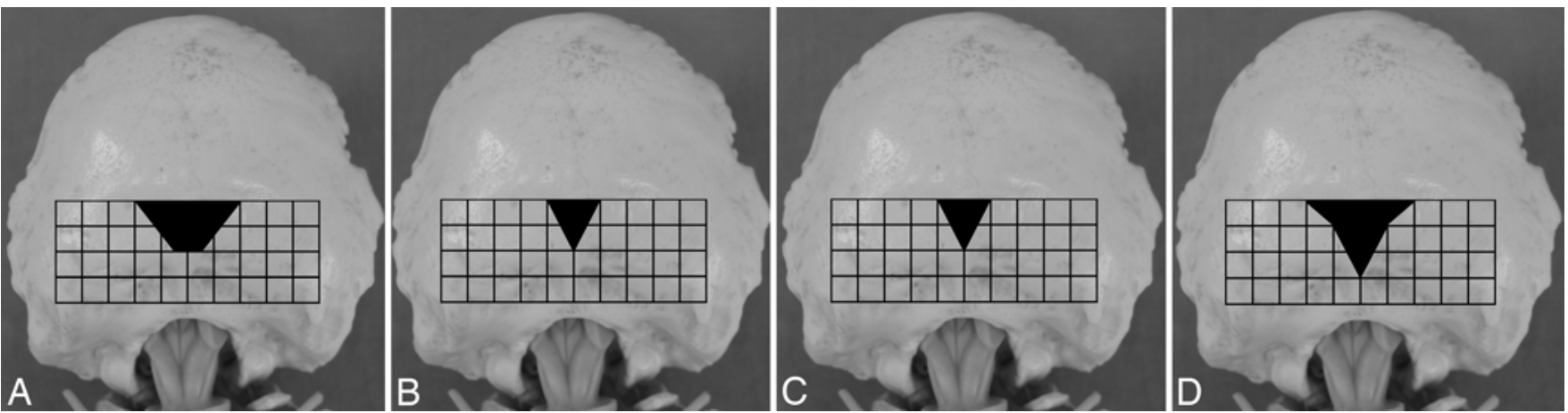

FIG. 2. Comparison of the map of safe zones for the placement of 8-mm screws according to Ebraheim et al. (A), Hertel and Hirschfelder (B), Naderi et al. (C), and the present study (D). Black areas represent zones where they showed that 8-mm screws should be inserted.

vest immobilization is sometimes required after surgery, and complications such as screw loosening, implant failure, and dural tears are occasionally observed. So far these problems remain unresolved. Abumi et al. ${ }^{1}$ reported the occurrence of occipital bone screw damage in 1 of 24 patients. They inserted an additional screw, and after surgery, halo-vest immobilization was used until bone union was attained. In addition, Deutsch et al. ${ }^{2}$ reported on 3 of 51 occipital cervical fusion cases of pseudarthrosis, in which implant failure occurred in 2 cases and revision surgery was required. Stable fixation and additional screw insertion positions at the time of revision surgery should be considered in such cases, and occipital bone morphological assessment would be required as well.

Stable fixation of the occipital bone to the cervical vertebrae requires screws $8 \mathrm{~mm}$ or more in length, according to Heywood et al. ${ }^{11}$ In response, a few authors have measured occipital bone thickness using CT in healthy subjects or morphological analysis in cadavers. $6,10,14,17,23$ For instance, Grob et al., ${ }^{6}$ who used CT, reported average thicknesses of $14 \mathrm{~mm}$ at the center of the superior nuchal line, $6.6 \mathrm{~mm}$ at the right paramedian, and $5.7 \mathrm{~mm}$ at the left paramedian. Moreover, these authors recommended inserting the screw at the median of the occipital bone. In addition, Olivier, ${ }^{17}$ Ebraheim et al., ${ }^{3}$ and Zipnick et al. ${ }^{23}$ measured the thickness of the occipital bone using cadaveric specimens, whereas Hertel and Hirschfelder ${ }^{10}$ and Naderi et al..$^{14}$ recorded measurements using CT.

In the present study, we documented occipital bone morphology in 105 healthy subjects using arbitrary CT slices to accurately measure the structure's thickness. Our results revealed a wider range of regions with thicknesses $>8 \mathrm{~mm}$ compared with previous reports (Fig. 2). Ebraheim et al. ${ }^{3}$ reported that 8 -mm screws should be inserted up to $2 \mathrm{~cm}$ lateral from the midline at the level of the EOP, $1 \mathrm{~cm}$ from the median crest at a level $1 \mathrm{~cm}$ inferior to the protuberance, and $0.5 \mathrm{~cm}$ from the crest at a level $2 \mathrm{~cm}$ inferior to the protuberance. Hertel and Hirschfelder ${ }^{10}$ and Naderi et al. ${ }^{14}$ reported that the area $>8 \mathrm{~mm}$ thick was up to $1 \mathrm{~cm}$ lateral to the EOP at the level of the superior nuchal line and $2 \mathrm{~cm}$ inferior to the EOP. In our study, the area was $2 \mathrm{~cm}$ lateral to the EOP at the level of the superior nuchal line and $3 \mathrm{~cm}$ inferior to the EOP. The above results suggest that it may be possible to effectively insert a screw over a wider area than the conventional reference range. In addition, our data suggest that there is sufficient space to make new bur holes for additional stability or in cases of screw loosening or implant failure. It is important to note that considerable individual variability was observed, as in previous studies. $3,10,14$ Therefore, we recommend measuring the thickness in every patient preoperatively. Post hoc calculations revealed that this study was adequately powered $(>80 \%)$ to detect a difference of area between the data of these authors and ours.

Finally, we demonstrated that the ratio of the trabecular bone to occipital bone thickness was about $30 \%$ in the central region and decreased inferiorly and laterally. Haher et al. ${ }^{8}$ reported that acceptable fixation is obtained with a unicortical screw around the EOP. However, unicortical fixation using a screw whose form is suitable for the ratio of trabecular and cortical bone thickness should be stronger against pullout.

\section{Conclusions}

This study in adults without head and neck disease offers the first detailed mapping of areas that would provide efficient occipital bone stabilization via the screw-rod method. We find that the area of occipital bone $>8 \mathrm{~mm}$ thick was up to $2 \mathrm{~cm}$ lateral to the EOP at the level of the superior nuchal line and $3 \mathrm{~cm}$ inferior to the EOP. Future studies should repeat these measurements in pediatric patients or patients with rheumatoid arthritis suspected to have different bone thicknesses or densities.

\section{References}

1. Abumi K, Takada T, Shono Y, Kaneda K, Fujiya M: Posterior occipitocervical reconstruction using cervical pedicle screws and plate-rod systems. Spine (Phila Pa 1976) 24:1425-1434, 1999

2. Deutsch H, Haid RW Jr, Rodts GE Jr, Mummaneni PV: Occipitocervical fixation: long-term results. Spine (Phila Pa 1976) 30:530-535, 2005

3. Ebraheim NA, Lu J, Biyani A, Brown JA, Yeasting RA: An anatomic study of the thickness of the occipital bone. Implications for occipitocervical instrumentation. Spine (Phila Pa 1976) 21:1725-1730, 1996

4. Fehlings MG, Errico T, Cooper P, Benjamin V, DiBartolo T: Occipito-cervical fusion with a $5 \mathrm{~mm}$ malleable rod and segmental fixation. Neurosurgery 32:198-207, 1993 
5. Flint GA, Hockley AD, McMillan JJ, Thompson AG: A new method of occipitocervical fusion using internal fixation. Neurosurgery 21:947-950, 1987

6. Grob D, Dvorak J, Panjabi M, Froehlich M, Hayek J: Posterior occipitocervical fusion. A preliminary report of a new technique. Spine (Phila Pa 1976) 16 (3 Suppl):S17-S24, 1991

7. Grob D, Schütz U, Plötz G: Occipitocervical fusion in patients with rheumatoid arthritis. Clin Orthop Relat Res (366):46-53, 1999

8. Haher TR, Yeung AW, Caruso SA, Merola AA, Shin T, Zipnick RI, et al: Occipital screw pullout strength. A biomechanical investigation of occipital morphology. Spine (Phila Pa 1976) 24:5-9, 1999

9. Hamblen DL: Occipito-cervical fusion. Indications, technique and results. J Bone Joint Surg Br 49:33-45, 1967

10. Hertel G, Hirschfelder H: In vivo and in vitro CT analysis of the occiput. Eur Spine J 8:27-33, 1999

11. Heywood AWB, Learmonth ID, Thomas M: Internal fixation for occipito-cervical fusion. J Bone Joint Surg Br 70:708711,1988

12. Hsu YH, Liang ML, Yen YS, Cheng H, Huang CI, Huang WC: Use of screw-rod system in occipitocervical fixation. J Chin Med Assoc 72:20-28, 2009

13. Matsunaga S, Ijiri K, Koga H: Results of a longer than 10 year follow-up of patients with rheumatoid arthritis treated by occipitocervical fusion. Spine (Phila Pa 1976) 25:1749_ 1753,2000

14. Naderi S, Usal C, Tural AN, Korman E, Mertol T, Arda MN: Morphologic and radiologic anatomy of the occipital bone. J Spinal Disord 14:500-503, 2001

15. Newman P, Sweetnam R: Occipito-cervical fusion. An operative technique and its indications. J Bone Joint Surg Br 51:423-431, 1969

16. Nockels RP, Shaffrey CI, Kanter AS, Azeem S, York JE: Occipitocervical fusion with rigid internal fixation: long-term follow-up data in 69 patients. J Neurosurg Spine 7:117-123, 2007

17. Olivier G: Biometry of the human occipital bone. J Anat 120:507-518, 1975

18. Ranawat CS, O'Leary P, Pellicci P, Tsairis P, Marchisello P, Dorr L: Cervical spine fusion in rheumatoid arthritis. J Bone Joint Surg Am 61:1003-1010, 1979

19. Sasso RC, Jeanneret B, Fischer K, Magerl F: Occipitocervical fusion with posterior plate and screw instrumentation. A long-term follow-up study. Spine (Phila Pa 1976) 19:23642368, 1994

20. Singh SK, Rickards L, Apfelbaum RI, Hurlbert RJ, Maiman D, Fehlings MG: Occipitocervical reconstruction with the Ohio Medical Instruments Loop: results of a multicenter evaluation in 30 cases. J Neurosurg 98 (3 Suppl):239-246, 2003

21. Thompson RC Jr, Meyer TJ: Posterior surgical stabilization for atlantoaxial subluxation in rheumatoid arthritis. Spine (Phila Pa 1976) 10:597-601, 1985

22. Vale FL, Oliver M, Cahill DW: Rigid occipitocervical fusion. J Neurosurg 91 (2 Suppl):144-150, 1999

23. Zipnick RI, Merola AA, Gorup J, Kunkle K, Shin T, Caruso SA, et al: Occipital morphology. An anatomic guide to internal fixation. Spine (Phila Pa 1976) 21:1719-1724, 1729-1730, 1996

24. Zygmunt SC, Christensson D, Säveland H, Rydholm U, Alund M: Occipito-cervical fixation in rheumatoid arthritis-an analysis of surgical risk factors in 163 patients. Acta Neurochir (Wien) 135:25-31, 1995

\section{Author Contributions}

Conception and design: Takebayashi, Morita. Acquisition of data: Morita, Takashima. Analysis and interpretation of data: all authors. Drafting the article: Morita. Critically revising the article: all authors. Reviewed submitted version of manuscript: all authors. Approved the final version of the manuscript on behalf of all authors: Takebayashi. Statistical analysis: Morita, Ohnishi. Administrative/technical/material support: Takebayashi.

\section{Supplemental Information}

\section{Previous Presentation}

Portions of this work were presented in poster form at the 86th Annual Meeting of the Japanese Orthopaedic Association held in Hiroshima, Japan, on March 24, 2013.

\section{Correspondence}

Tsuneo Takebayashi, Department of Orthopedic Surgery, Sapporo Medical University School of Medicine, South-1, West-17, Chuo-ku, Sapporo, Hokkaido 060-8556, Japan. email: takebaya@ sapmed.ac.jp. 